\title{
Razvoj vprašalnika o delovni zavzetosti in motivaciji zaposlenih
}

\author{
Marija Paladin* \\ Slovenske železnice d.o.o., Kolodvorska 11, 1000 Ljubljana \\ marija.paladin@gmail.com
}

\section{Povzetek:}

Raziskovalno vprašanje (RV): Kakšna je pot razvoja vprašalnika o delovni zavzetosti in motivaciji zaposlenih, ki je lahko tudi kažipot za razvoj organizacije?

Namen: Cilj in namen je predstaviti razvoj večdimenzionalnega, samo aplikativnega vprašalnika, ki na podlagi samoocene ponudi vpogled $\mathrm{v}$ stanje delovne zavzetosti in motivacije zaposlenih ter ponudi izhodišče za izboljšave na ravni organizacije.

Metoda: Predstavljene so faze razvoja vprašalnika $\mathrm{v}$ katerih se prepletata kvantitativna in kvalitativna metodologija. $\mathrm{V}$ članku je poudarek na rezultatih kvantitativne faze - to je drugega testnega anketiranja.

Rezultati: Oblikovana lestvica skozi obe fazi testnega anketiranja kaže na visoko notranjo konsistentnost. V drugem testnem anketiranju se izoblikujejo 3 faktorji skozi katere se dejavniki delovne zavzetosti in motivacije zaposlenih predstavijo po sklopih 'delovni odnosi in sodelovanje', 'pogoji dela' ter 'možnosti za delovno samorealizacijo.

Organizacija: Spremljanje delovne zavzetosti in motivacije zaposlenih za organizacijo na eni strani pomeni izhodišče za konkretno delo na razvojno kadrovskem področju, na drugi strani pa informacijo o morebitnih šibkih točkah, ki jih za izboljšanje sovje konkurenčne pozicije mora ojačati.

Družba: Delovno zavzeti in motivirani posamezniki so nosilec razvoja in produktivnosti ter iskanja optimalnejših rešitev v konstantno spreminjajočem se poslovnem in družbenem okolju.

Originalnost: Prispevek te študije je dvojni - metodološko raziskovalni in praktični. Razviti vprašalnik praktikom ter strokovnjakom in raziskovalcem ponuja možnost uporabe v našem okolju oblikovane in testirane lestvice tako za praktično uporabo v kadrovski praksi organizacije kot tudi za namen nadaljnjih raziskav.

Omejitve/nadaljnje raziskovanje: Potek razvoja vprašalnika je predstavljena kot odprta pot $\mathrm{s}$ četrto fazo, ki ni zaključena in je kot taka tudi izpostavljena $v$ članku. Zato je jasno izraženo vabilo $\mathrm{k}$ nadaljnjim testiranjem tudi $\mathrm{v}$ prihodnje.

Ključne besede: delovna zavzetost, motivacija, vodenje, razvoj kadrov, razvoj organizacije, vprašalnik.

\section{Uvod}

Merjenje delovne zavzetosti motivacije zaposlenih ni novost na kadrovskem področju. Zavzetost zaposlenih je na razvojno kadrovskem področju vedno bolj prepoznana kot eden najpomembnejših dejavnikov za spremljanje ključnih zaposlenih in njihov nadaljnji razvoj (Kwon in Park, 2019, str. 352, 353). V članku bo predstavljen postopek razvoja vprašalnika o delovni zavzetosti in motivaciji zaposlenih. Podrobneje bodo predstavljeni rezultati drugega testnega anketiranja, končna lestvica vprašalnika ter vsebinski sklopi, ki jih meri. Ponudili 
bomo možnosti za interpretacijo rezultatov merjenja ter nadaljnje usmeritve. Prispevek te študije je dvojni - metodološko raziskovalni in praktični. Razviti vprašalnik praktikom (npr. podjetjem in kadrovskim službam) ter strokovnjakom in raziskovalcem ponuja možnost uporabe $\mathrm{v}$ našem okolju oblikovane in testirane lestvice tako za praktično uporabo $\mathrm{v}$ kadrovski praksi organizacije kot tudi za namen nadaljnjih raziskav. Cilj oblikovanja in testiranja vprašalnika, ki bo predstavljen v članku je bil razviti večdimenzionalni, samo aplikativni vprašalnik, ki na podlagi samoocene ponudi vpogled $\mathrm{v}$ stanje delovne zavzetosti in motivacije zaposlenih. Na drugi strani pa zaradi svoje oblike in dejavnikov, ki jih zajema izpostavi izhodiščne točke za razvoj organizacije na področju dela s človeškimi viri.

Na tem mestu se odpira vprašanje, zakaj razvijati nov merski instrument, ne pa uporabiti obstoječe merske lestvice. Med pomembnejšimi težavami so izzivi prevoda merskih instrumentov, saj je večina vprašalnikov izvirno tujih, ter vpliva prevoda na vsebino in razumljivost posameznega indikatorja (izjave) iz vprašalnika in posledično na vsebino merjenja. Dodatna težava je dolžina vprašalnika, saj so nekateri zelo kakovostni in celostno zastavljeni vprašalniki lahko zelo dolgi in zahtevajo več časa za izpolnjevanje. Rezultati raziskav v zvezi z vplivom dolžine vprašalnika na stopnjo odziva kažejo, da lahko dolžina vprašalnika vpliva na pojav manjkajočih vrednosti in odločitev za sodelovanje (Iglesias in Torgerson, 2000, str. 2020). Za uporabo katerega koli merskega instrumenta v vsakdanji, sprotni kadrovski in poslovni praksi podjetja je $\mathrm{v}$ vsakem primeru nujno, da je vprašalnik optimiziran tako $\mathrm{z}$ vidika ustreznosti vsebine kot tudi dolžine vprašalnika s ciljem ponuditi kakovostno informacijo oziroma izhodišče za nadaljnje konkretne korake ob hkratnem čim manjšem motenju delovnega procesa.

\section{Teoretična izhodišča}

Pri delovni zavzetosti gre za (motivacijski) dejavnik oziroma stanje v katerem imajo zaposleni željo uresničiti/doseči delovne in organizacijske cilje ter naloge, $\mathrm{v}$ katerem zaposleni zavzeto/navdušeno sodelujejo pri delu in delujejo tako, da podpirajo in promovirajo interese organizacije (Bakertzis in Myloni, 2020, str. 2-3). Delovna zavzetost se v tem smislu nanaša na stopnjo, do katere je posameznik fizično, kognitivno in čustveno vpet $\mathrm{v}$ delovno vlogo (Kahn v Weer in Greenhaus, 2020, str. 4). V osnovi gre tudi za to, da posameznik v konkretnih situacijah (na primer pri delu) prostovoljno izkazujejo vedenja, ki izražajo povezavo med njim in konkretno vlogo (Gupta in Shukla, 2018) v smislu delovne proaktivnosti, predanosti delu in vpetost $\mathrm{v}$ konkretno nalogo. Pri čemer delovna proaktivnost predstavlja stanje, $\mathrm{v}$ katerem je zaposleni poln energije, poleta in pripravljenosti na delo, predanost predstavlja obseg smiselnosti dela za zaposlenega in njegov ponos ob tem. Vpetost kaže na to, do katere mere so se zaposleni pripravljeni prepustiti, da njihovo delo posrka vso njihovo pozornost in koncentracijo (W. B. Schaufeli idr., 2002, str. 74-75). Delo mora zaposleni dojemati kot smiselno, sicer bo delovno manj zavzet. Ravno tako je za delovno zavzetost pomembno sovpadanje posameznika z vsebino dela, odnosi v delovnem okolju (s sodelavci, vodjo), možnostjo izraziti se, ustreznostjo zahtevnosti dela (psihična in fizična) in sredstvi za delo, varnostjo zaposlitve in varnostjo na delu (May idr., 2004, str. 14-18). 
Delovno zavzetost zaposlenih sooblikujejo različni dejavniki. Zelo pomemben pri tem je način upravljanja s človeškimi viri (Chaudhary idr., 2012; Sekhar idr., 2018).

Intenzivna tekmovalnost in povečana negotovost, ki sta značilna za današnje poslovno okolje predstavljata poseben izziv za doseganje produktivnosti na delu (Chaudhary idr., 2012, str. 370) kar lahko negativno sooblikuje delovno zavzetost zaposlenih in njihovo uspešnost pri delu. Na drugi strani pa ima zaupanje $\mathrm{v}$ sodelavce in vodje pozitiven učinek na delovno zavzetost (Ho in Astakhova, 2018, str. 19). Zavzeti in motivirani zaposleni ostajajo pri delodajalcu (McCarthy idr., 2020), so bolj delovno fleksibilni in produktivni, inovativni ter uspešnejši pri delu (Bakertzis in Myloni, 2020; Sekhar idr., 2018). Hkrati pa to pozitivno vpliva tudi na odjemalce in poslovno uspešnost podjetja kot celote. Težko je namreč ustvariti in zadržati motivirane in zavzete odjemalce/stranke, če nimamo in ne ohranjamo ustrezne ravni motiviranosti ter delovne zavzetosti zaposlenih (Inc, 2007). Ugotovitve kažejo tudi, da višja zavzetost pri delu pozitivno vpliva na zniževanje bolniške odsotnosti in na manj pogoste poškodbe pri delu (slednje je tesno povezano tudi s kakovostjo opravljanja dela).

A preden bo postopek oblikovanja in testiranja vprašalnika predstavljen je nujno postaviti ločnico med delovno zavzetostjo in motivacijo zaposlenega ter zadovoljstvom z delom, ki se je v zadnjem času ravno tako precej populariziral. Zadovoljstvo pri delu, je prijetno pozitivno čustveno stanje kot rezultat dobrega počutja na delu in pozitivnega dojemanja svojega dela (Lock v Danish in Usman, 2010, str. 160). Gre za čustven odziv posameznika in subjektiven občutek posameznika, ki odraža obseg, v katerem določeno delo izpolnjuje potrebe posameznika (povzeto po Griffin idr., 2010, str. 242). Medtem, ko je zadovoljstvo zaposlenih koristno za to, da želeni kader zadržimo v podjetju, ni dovolj, da bi zagotovili produktivnost kadra. Na tej točki je pomembna delovna zavzetost, ki vpliva ne le na to, ali bo delavec ostal v podjetju (ker je tu zadovoljen) temveč tudi, koliko se bo delavec pripravljen angažirati pri delu in koliko bo pri delu produktiven. Pri delovni zavzetosti pa gre za dejavnik, ki je tesneje neposredno povezan z uspešnostjo in učinkovitostjo dela. Delovno zavzetost lahko v tem smislu razumemo kot potencialno pomembno konkurenčno prednost podjetja (Kim idr., 2012, str. 267). Na drugi strani je lahko zaposleni zadovoljen z delom, ne da bi v delo veliko vlagal. Delovna zavzetost zaposlenih presega zgolj merjenje zadovoljstva s plačo, urnikom, vodjo, sodelavci. Zadovoljstvo zaposlenih je, sicer pomembno, a predstavlja zgolj začetno točko, na kateri lahko podjetje gradi in razvija svoje zaposlene in njihovo produktivnost.

Na področju delovne zavzetosti in motivacije zaposlenih je razvitih več orodij, na primer UWES vprašalnik o delovni zavzetosti (ang. The Utrecht Work Engagement Scale) v krajši in daljši različici (W. Schaufeli \& Bakker, 2004). Daljša različica obsega 17 vprašanj v treh sklopih: vitalnost (vigor), predanos (dedication) in vpetost (absorption). Drugi primer je lestvica treh sklopov po deset dejavnikov delovne zavzetosti, ki je bila objavljena v letu 2019 in je nastala pod okriljem izkušenih kadrovskih managerjev in strokovnjakov na področju (Shrotryia in Dhanda, 2019). Prvi sklop govori o usklajenosti organizacije in posameznika, drugi o emocionalni pripadnosti $\mathrm{v}$ delovnem okolju, tretji pa o usmerjenosti $\mathrm{v}$ delovanje in produktivnost (Shrotryia in Dhanda, 2019, str. 4). Tretji primer lestvice predstavlja Gallupov 
q12 vprašalnik dvanajstih indikatorjev zavzetosti (Bakovnik, 2018), ki sodi med mednarodno bolj znane in pogosteje uporabljane instrumente na področju merjenja delovne zavzetosti. Lestvico tvorijo štirje ključni vsebinski sklopi delovne zavzetosti: možnost za rast, zavedanje o tem, čemu delavec pripada, kaj lahko ponudi organizaciji in delovnemu okolju ter kaj iz tega istega dobi sam (Inc, 2007). V primeru Gallupovega vprašalnika gre za ugotavljanje stanja pogojev v delovnem okolju za močno delovno zavzetost zaposlenega.

Razviti smo želeli vprašalnik, ki bo sledil ključnim motivacijskim dejavnikom, ki usmerjajo delovanje posameznika po zgledu lestvice 15 delovnih motivov (Pogačnik, 2000), hkrati pa smo želeli oblikovati instrument, ki ne bo usmerjen zgolj v posameznika, kot to velja za ubeseditev UWES vprašalnika (npr. Pri svojem delu prekipevam od energije.) ali lestvice 30 indikatorjev, ki je nastala pod okriljem izkušenih kadrovskih managerjev in strokovnjakov na področju (Shrotryia in Dhanda, 2019), temveč bo nudil informacijo tudi o organizaciji sami v smislu stanja temeljnih pogojev za optimalno delovno zavzetost, ki izhajajo iz motivacijskih dejavnikov in izpostavljajo potencial za nadaljnje izboljšave. Na tej točki je ubeseditev našega vprašalnika bližje Gallupovem Q12 vprašalniku, ki daje vpogled tudi v konkretne delovne pogoje (npr. Imam sredstva in opremo, ki jih potrebujem za opravljanje svojega dela.). Končni namen razvoja vprašalnika o delovni zavzetosti in motivaciji, ki je predstavljen $\mathrm{v}$ pričujočem članku, je namreč oblikovanje merskega instrumenta, ki ga bodo organizacije skozi ugotavljanje stanja delavčeve zavzetosti lahko uporabile kot del letnega razgovora, svetovanja in načrtovanja kariernega razvoja ter tudi načrtovanja izboljšav na ravni organizacije. Naš namen je bil preseči zgolj vpogled v eno stran (to je posameznega delavca ali zaposlene kot celoto), temveč analizo razširiti na ugotavljanje stanja v organizaciji sami. Natančneje $v$ iskanje potenciala za izboljšanje. Oba vidika namreč sooblikujeta pogoje in stanje delovne zavzetosti ter posledično rezultate dela.

\section{Metoda}

Razvoj vprašalnika o delovni zavzetosti in motivaciji zaposlenih je po zgledu razvoja številnih drugih vprašalnikov (Enosh idr., 2015; Fox idr., 2015; Paladin idr., 2020; Schembre idr., 2015; Velagapudi in Ray, 2017) potekal v več fazah. Te obsegajo oblikovanje izhodiščnega nabora vprašanj, prvo pilotno anketiranje, drugo pilotno anketiranje in predloge za nadaljnjo razvojno pot vprašalnika. Slika 1 prikazuje model raziskave skozi faze razvoja vprašalnika. 


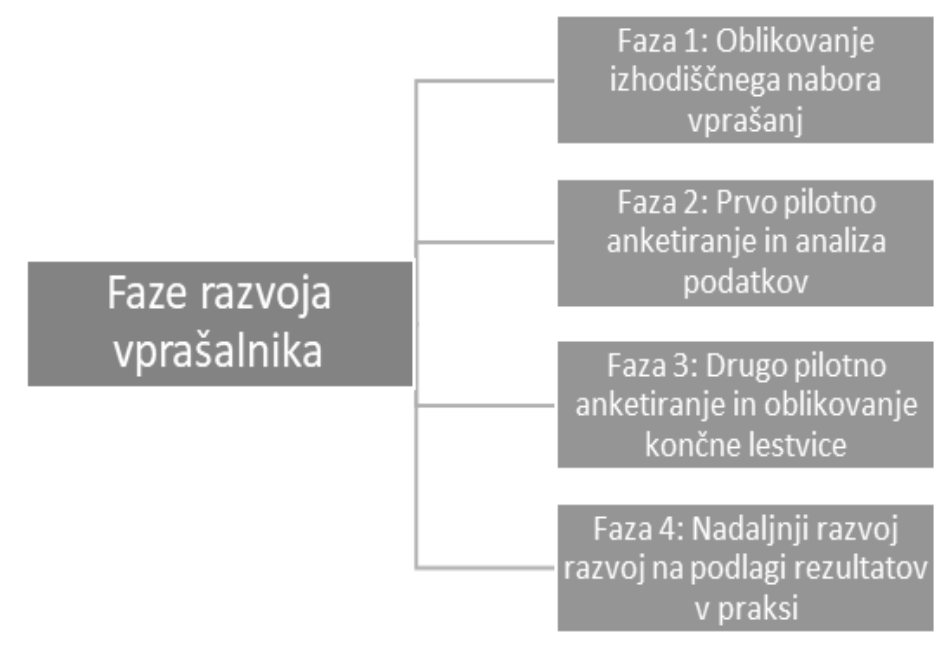

Slika 1. Model raziskave skozi faze razvoja vprašalnika.

$\mathrm{V}$ prvi in delu druge faze razvoja vprašalnika je bil uporabljen pristop integracije kvantitativne in kvalitativne metodologije $\mathrm{v}$ nadaljnjih fazah pa je težišče na kvantitativni metodologiji. Vse faze razvoja bodo na kratko predstavljene $v$ tem poglavju njihovi rezultati pa strnjeno $\mathrm{v}$ poglavju o rezultatih, kot uvod $\mathrm{v}$ fazo, ki bo podrobneje predstavljena $\mathrm{v}$ tem članku, to je drugo testno anketiranje in njegovi rezultati.

Pri oblikovanju izhodiščnega nabora vprašanj so bila upoštevana izhodišča več uveljavljenih vprašalnikov, ki že obstajajo na področju spremljanja zavzetosti in delovne motivacije. Najpomembnejši izhodišči sta bili lestvica 15 delovnih motivov (Pogačnik, 2000) slovenskega avtorja, ki je bila razvita, preverjena in testirana v slovenskem okolju in, ki je bila $\mathrm{v}$ daljšem časovnem obdobju velikokrat uporabljena $\mathrm{v}$ različnih slovenskih podjetjih ter novejša lestvica 30 dejavnikov delovne zavzetosti (Shrotryia in Dhanda, 2019). Gallupov q12 vprašalnik (Bakovnik, 2018) dvanajstih indikatorjev zavzetosti je koristil v smislu primerjanja vsebinskih sklopov, ki so se oblikovali v prvem testnem anketiranju našega vprašalnika z vsebinskimi sklopi Gallupovega q12 vprašalnika (Bakovnik, 2018) ter v upoštevanju izhodišča, ki fokus z zgolj posameznika širi na celotno organizacijo.

Izhodiščna različica vprašalnika je zajemala 19 indikatorjev/izjav pri katerih so delavci podali oceno o tem, koliko posamezna izjava drži ali ne drži v njihovem primeru v obdobju zadnjega leta. Odgovarjali so na 5 stopenjski lestvici Likartovega tipa od 1 nikakor ne drži do 5 popolnoma drži. Vsebina izjav je zajemala več področij (natančneje v tabeli 1 in 2).

Prvo pilotno anketiranje je bilo izvedeno s pomočjo spletnega anketnega vprašalnika in je imelo tri cilje. Najprej preverjanje sprejemljivosti dolžine vprašalnika kar je za namen redne uporabe $\mathrm{v}$ praksi podjetja zelo pomembno. Drugi pomemben namen prvega testnega anketiranja je bilo preverjanje vsebinske razumljivosti in relevantnosti vsebine (izjav) vprašalnika $v$ smislu preverjanja interpretacij izjav, ki tvorijo vprašalnika pri preučevanih subjektih (Kogovšek, 2005, str. 269) (zaposlenih) zaradi zagotavljanja kar se da visoke stopnje veljavnosti merskega instrumenta. Anketirani so bili pozvani, da se opredelijo do 
dolžine vprašalnika, razumljivosti izjav in tega kar merijo ter $\mathrm{k}$ posredovanju morebitnih predlogov za dopolnitev nabora ali dejavnikov, ki bi jih vprašalnik moral dodatno vključevati. Rezultati so pokazali, da je bila dolžina vprašalnika ustrezna, vsebina pa razumljiva. Tretji namen testnega anketiranja je bil zbrati podatke za namen izvedbe faktorske analize zaradi preveritve ali se oblikujejo vsebinski sklopi, ki podrobneje razčlenijo prvotni nabor vprašanj o delovni zavzetosti in motivaciji zaposlenih.

Morebitno prisotnost pomembnejših vsebinskih sklopov oziroma dimenzij, ki jih tvori več indikatorjev/izjav iz vprašalnika, ki je predstavljen v tem članku, smo preverjali po zgledu sklopov iz vprašalnika Gallupov Q12 (Bakovnik, 2018) in po zgledu novejše lestvice 30 indikatorjev (Shrotryia in Dhanda, 2019). In sicer smo po zgledu Gallupa (Inc, 2007) preverjali, ali se bodo oblikovali štirje ključni vsebinski sklopi delovne zavzetosti možnost za rast, zavedanje pripadnosti, kaj lahko ponudi organizaciji in kaj organizacija njemu. Oziroma ali bo ustreznejši pristop 3 dimenzij (Shrotryia in Dhanda, 2019) o usklajenosti delavca in organizacije, emocionalni pripadnosti in usmerjenosti v akcijo in produktivnost.

Tudi drugo pilotno anketiranje je bilo izvedeno s pomočjo spletnega anketnega vprašalnika $\mathrm{V}$ katerem so bili k sodelovanju povabljeni obiskovalci različnih spletnih strani in forumov. Hkrati so bili povabljeni, da povezavo do spletne ankete delijo z drugimi kontakti/uporabniki spleta. Glede na navedeno gre za priložnosten vzorec, ne slučajen. Vabilu se je odzvalo 200 posameznikov. Po izvedenem testnem anketiranju, je bila izvedena analiza dobljenih rezultatov. V drugem testnem anketiranju so anketirani odgovarjali zgolj na vprašanja vključena $\mathrm{v}$ tesni vprašalnik brez demografskih ali drugih vprašanj. Povprečne vrednosti dosežene pri posameznem dejavniku so predstavljene $\mathrm{v}$ tabeli 1.

Samoocenjevanje na katerem sloni vprašalnik se kaže kot koristen in praktičen pristop, ki se pogosto uporablja na različnih področjih, od ocenjevanja kompetenc (Curyto in Vriesman, 2015; Darling in Gallagher, 2016), v povezavi z izobraževanjem (Stufflebeam in Wingate, 2016) do ocenjevanja potreb po dodatnem usposabljanju in izobraževanju (Bromley, Boran in Myddelton, 2016). Kljub morebitni pristranskosti, ki je lahko prisotna v primeru samoocenjevanja je prednost te metode, poleg njene praktičnosti, tudi to, da se posameznik zaveda informacij o sebi, ki niso na voljo drugim (Allen in Van der Velden, 2005, str. 8-11) in jih skozi samooceno lahko ponudi. Na eni strani je mogoče morebitno pristranskost metode samoocenjevanja preveriti in minimizirati skozi triangulacijo ter primerjavo in iskanje morebitnih neskladnosti med ocenami iz različnih virov, na primer med oceno nadrejenega in samooceno (Staley in Shockley-Zalabak, 1986), vendar je treba poudariti, da tudi druge metode ocenjevanja, na primer s strani nadrejenih ali sodelavcev, niso nujno objektivne in so lahko pristranske.

Analiza podatkov je zajemala izračun opisnih statistik, izvedbo faktorske analize ter na njeni podlagi izračun združenih spremenljivk po posameznem faktorju. Zanesljivost in veljavnost merskega instrumenta kot celote oziroma posameznih faktorjev, ki so se izoblikovali v faktorski analizi smo preverjali v več korakih. Najprej pri samem oblikovanju izhodiščne 
verzije vprašalnika skozi opiranje na obstoječe, že uveljavljene merske lestvice, nato pa skozi preverjanje razumljivosti v prvem testnem anketiranju. Notranjo konsistentnost konstruktov smo preverjali z izračunom Cronbachovega alfa koeficienta.

\section{Rezultati}

\subsection{Rezultati prvega testnega anketiranja}

Po izvedenem prvem testnem anketiranju, je bila izvedena analiza dobljenih rezultatov na podlagi 89 vprašalnikov pri katerih so anketiranci odgovorili na vsa vprašanja o delovni zavzetosti in motivaciji. $\mathrm{V}$ faktorski analizi izvedeni na podatkih zbranih $\mathrm{v}$ prvem pilotnem anketiranju so se izoblikovali 4 sklopi, ki so vsebinsko primerljivi z vsebinskimi sklopi iz Gallupove lestvice. Štirje sklopi, ki so se oblikovali v prvem testnem anketiranju so čemu pripadam, kaj lahko ponudim, moje mikro okolje ter podlage za rast in razvoj. Število izjav v posameznem sklopu precej enakomerno (4 oziroma 5, več $\mathrm{v}$ tabeli 1). Izvedena je bila faktorska analiza (PAF metoda s pravokotno Varimax rotacijo) v 2 ponovitvah (1. zvedba z vsemi izjavami, 2. izvedba brez dveh izjav, ki sta odstopali v prvi analizi). Cronbachov alfa koeficient notranje konsistentnosti je pokazal za celotno končno lestvico vrednost 0,92 (pri posameznemu sklopu pa od 0,79 do 0,81 ) kar kaže na dobro notranjo konsistentnost lestvice in njenih podsklopov.

Ugotovitve faktorske analize so kazale, da je iz nabora izjav smiselno izključiti dve izjavi od 19, in sicer sta pomembneje odstopali izjavi o ustreznosti plačila ter izjava o možnostih za strokovni razvoj. Odstopanje izjave o zadovoljstvu s plačilom za opravljeno delo v prvem testnem anketiranju niti ni presenetljivo, saj rezultati drugih avtorjev tudi pokažejo, da so zaposleni redko zadovoljni s plačo in jo ocenjujejo nižje kot druge dejavnike v delovnem okolju (Pogačnik, 2000, str. 113). Tudi v obeh testnih anketiranjih za potrebe razvoja v članku predstavljenega vprašalnika (rezultati drugega so v tabeli 1) se je pokazalo, da je ocena plačila za delo med najnižjimi. Druga izjava, ki je je v prvem testnem anketiranju odstopala od preostalega nabora, je bila izjava o obstoju možnosti za strokovni razvoj. Kljub temu smo že po prvem testiranju za uporabo v praksi svetovali, da se dejavnika obravnavata kljub odstopanju, vendar zaradi nakazanega odstopanja, ločeno od lestvice delovne zavzetosti in motivacije zaposlenih.

Na tej podlagi je bil pripravljen strokovni članek v katerem so bili strnjeno predstavljeni rezultati prvih dveh faz razvoja, lestvica, ki se nakazuje in predlogi izhodišč za interpretacijo (Paladin, 2020). Hkrati je bilo objavljeno vabilo k uporabi, kot izhodišče za nadaljnje preverjanje uporabnosti vprašalnika $\mathrm{v}$ praksi in zbiranje odzivov nanj. Pred začetkom tretje faze testiranja so prišle tudi prve pozitivne povratne informacije o praktični uporabnosti lestvice $\mathrm{v}$ praksi $\mathrm{v}$ povezavi $\mathrm{s}$ spremljanjem novozaposlenih in neželenih odhodov iz organizacije. 


\subsection{Rezultati drugega testnega anketiranja}

\subsubsection{Opisne statistike}

$\mathrm{V}$ tabeli 1 so navedene opisne statistike drugega testnega anketiranja za indikatorje vključene v vprašalnik. Za nadaljnjo analizo je zelo pomembno, da se vrednosti rezultatov pri večini indikatorjev porazdeljujejo približno normalno, in sicer so vrednosti koeficientov asimetrije in sploščenosti ležijo med 1 in -1 . Nekateri avtorji kot sprejemljivo vrednost koeficienta sploščenosti za ugotavljanje normalne porazdelitve navajajo vrednost med -2 in 2 ter koeficienta asimetrije pod 3 (Chemingui \& Ben lallouna, 2013). Upoštevajoč navedeno, se vrednosti rezultatov drugega testnega anketiranja za vse indikatorje porazdeljujejo normalno.

Najnižje povprečne vrednosti so pri indikatorjih, ki ocenjujeta ustreznost plačila za opravljeno delo in obstoj možnosti za napredovanje. Na drugi strani so najvišje povprečne vrednosti pri oceni samostojnosti opravljanja dela, razpoložljivosti potrebnih sredstev za opravljanje delovnih nalog, jasnosti pričakovanj s strani vodje, kakovost sodelovanja s sodelavci ter kakovosti opravljenega dela sodelavcev. 
Tabela 1: Opisne statistike dejavnikov vključenih v vprašalnik.

\begin{tabular}{|c|c|c|c|c|c|c|c|c|}
\hline Dejavnik kot je naveden v vprašalniku. & Dejavnik okrajšano & $\mathbf{N}$ & Min & Maks & $\mathbf{M}$ & $\begin{array}{l}\text { Stand. } \\
\text { odklon }\end{array}$ & $\begin{array}{l}\text { Koef. } \\
\text { Asim. }\end{array}$ & $\begin{array}{l}\text { Koef. } \\
\text { Splošč. }\end{array}$ \\
\hline Svoje delo opravljam samostojno. & samostojnost pri delu & 200 & 1 & 5 & 4,42 & 0,796 & $-1,450$ & 2,050 \\
\hline $\begin{array}{l}\text { Imam potrebna sredstva za opravljanje delovnih } \\
\text { nalog. }\end{array}$ & delovna sredstva & 200 & 1 & 5 & 4,09 & 0,993 & $-1,176$ & 1,072 \\
\hline Vem, kaj vodja od mene pričakuje. & pričakovanja vodje & 200 & 1 & 5 & 4,08 & 0,979 & $-1,103$ & 0,867 \\
\hline S sodelavci dobro sodelujemo. & sodelovanje v delovnem okolju & 200 & 1 & 5 & 4,04 & 0,915 & $-0,903$ & 0,531 \\
\hline Moji sodelavci dobro opravljajo svoje delo. & kakovost dela sodelavcev & 200 & 1 & 5 & 4,02 & 0,885 & $-1,269$ & 2,231 \\
\hline $\begin{array}{l}\text { Moj strokovni razvoj in usposabljanje je moja } \\
\text { odgovornost. }\end{array}$ & odgovornost za strokovni razvoj & 200 & 1 & 5 & 3,89 & 1,041 & $-0,694$ & $-0,124$ \\
\hline Zadovoljen sem z vsebino mojega dela. & dojemanje vsebina dela & 200 & 1 & 5 & 3,88 & 1,089 & $-1,071$ & 0,702 \\
\hline Delovni pogoji so dobri. & delovni pogoji & 200 & 1 & 5 & 3,81 & 1,105 & $-0,769$ & $-0,102$ \\
\hline V podjetju se dobro počutim. & počutje v delovnem okolju & 200 & 1 & 5 & 3,77 & 1,165 & $-0,900$ & 0,026 \\
\hline $\begin{array}{l}\text { Občutek imam, da je moje delo za podjetje } \\
\text { pomembno. }\end{array}$ & občutek pomembnosti dela & 200 & 1 & 5 & 3,72 & 1,184 & $-0,882$ & 0,146 \\
\hline $\begin{array}{l}\mathrm{Na} \text { delovnem mestu je moje mnenje } \\
\text { upoštevano. }\end{array}$ & občutek upoštevanosti & 200 & 1 & 5 & 3,68 & 1,172 & $-0,923$ & 0,049 \\
\hline Vodja upošteva predloge zaposlenih. & upoštevanje delavčevih predlogov s strani vodje & 200 & 1 & 5 & 3,66 & 1,154 & $-0,872$ & 0,166 \\
\hline $\begin{array}{l}\text { Imam možnost pokazati kaj znam in predlagati } \\
\text { izboljšave. }\end{array}$ & možnosti pokazati znanje in podati predloge & 200 & 1 & 5 & 3,64 & 1,182 & $-0,818$ & $-0,084$ \\
\hline Vodja pohvali dobro opravljeno delo. & prisotnost pohval s strani vodij & 200 & 1 & 5 & 3,58 & 1,305 & $-0,570$ & $-0,715$ \\
\hline Komunikacija v delovnem okolju je dobra. & komunikacija v delovnem okolju & 200 & 1 & 5 & 3,53 & 1,169 & $-0,731$ & $-0,265$ \\
\hline Imam možnost za strokovni razvoj. & možnost za strokovni razvoj & 200 & 1 & 5 & 3,48 & 1,287 & $-0,521$ & $-0,744$ \\
\hline Količina dela, ki jo prejemam je primerna. & količina dela & 200 & 1 & 5 & 3,43 & 1,158 & $-0,433$ & $-0,682$ \\
\hline Zadovoljen sem s plačilom za svoje delo. & plačilo za opravljeno delo & 200 & 1 & 5 & 2,76 & 1,040 & $-0,040$ & $-0,256$ \\
\hline V podjetju je dovolj možnosti za napredovanje. & možnosti za napredovanje & 200 & 1 & 5 & 2,73 & 1,333 & 0,082 & $-1,191$ \\
\hline
\end{tabular}




\subsubsection{Rezultati faktorske analize}

$\mathrm{Na}$ zbranih podatkih smo izvedli smo faktorsko analizo $\mathrm{z}$ namenom preveritve ali se oblikujejo vsebinski sklopi, ki podrobneje razčlenijo lestvico delovne zavzetosti in motivacije zaposlenih. Izvedena je bila faktorska analiza z metodo PAF (metoda glavnih osi) s pravokotno Varimax rotacijo. Rotirana faktorska rešitev je jasneje pokazala razdelitev indikatorjev po faktorjih. Najprimernejša je bila rešitev s tremi faktorji, ki zajemajo vsak svoj nabor $\mathrm{v}$ izhodiščno različico vprašalnika vključenih vprašanj/spremenljivk. $V$ tabeli 2 so predstavljeni vsebinski sklopi, ki so se oblikovali po prvem in drugem testnem anketiranju. Cronbachov alfa koeficient notranje konsistentnosti je pokazal za celotno lestvico 19 izjav vrednost 0,932 kar kaže na dobro notranjo konsistentnost lestvice glede na to, da je sprejemljiva raven vrednosti koeficienta nad 0,7 (Tavakol in Dennick, 2011).

Tabela 2. Vsebinski sklopi po prvem in drugem pilotnem testiranju vprašalnika

\begin{tabular}{|c|c|c|c|}
\hline $\begin{array}{l}\text { Faktor/sklop iz } \\
\text { drugega } \\
\text { testiranja }\end{array}$ & Dejavnik & $\begin{array}{l}\text { Faktor. } \\
\text { utež }\end{array}$ & $\begin{array}{l}\text { Faktor/sklop iz prvega } \\
\text { testiranja }\end{array}$ \\
\hline \multirow{5}{*}{$\begin{array}{l}\text { Delovni odnosi } \\
\text { in sodelovanje }\end{array}$} & kakovost dela sodelavcev & 0,616 & Čemu pripadam \\
\hline & komunikacija v delovnem okolju & 0,737 & Čemu pripadam \\
\hline & sodelovanje v delovnem okolju & 0,595 & Čemu pripadam \\
\hline & počutje v delovnem okolju & 0,633 & Moje mikro okolje \\
\hline & dojemanje vsebine dela & 0,453 & Moje mikro okolje \\
\hline \multirow[t]{6}{*}{ Pogoji dela } & količina dela & 0,555 & Moje mikro okolje \\
\hline & delovni pogoji & 0,659 & Odstopa $\mathrm{v}$ prvem testiranju \\
\hline & delovna sredstva & 0,560 & Podlage za rast in razvoj \\
\hline & možnosti za napredovanje & 0,626 & Podlage za rast in razvoj \\
\hline & plačilo za opravljeno delo & 0,741 & Podlage za rast in razvoj \\
\hline & prisotnost pohval s strani vodij & 0,526 & Podlage za rast in razvoj \\
\hline \multirow{8}{*}{$\begin{array}{l}\text { Možnosti za } \\
\text { delovno } \\
\text { samorealizacijo }\end{array}$} & občutek upoštevanosti & 0,663 & Čemu pripadam \\
\hline & pričakovanja vodje & 0,525 & Kaj lahko ponudim \\
\hline & $\begin{array}{l}\text { možnosti pokazati znanje in podati } \\
\text { predloge }\end{array}$ & 0,768 & Kaj lahko ponudim \\
\hline & občutek pomembnosti dela & 0,737 & Kaj lahko ponudim \\
\hline & $\begin{array}{l}\text { upoštevanje delavčevih predlogov s } \\
\text { strani vodje }\end{array}$ & 0,658 & Kaj lahko ponudim \\
\hline & samostojnost pri delu & 0,533 & Moje mikro okolje \\
\hline & možnost za strokovni razvoj & 0,515 & Odstopa v prvem testiranju \\
\hline & odgovornost za strokovni razvoj & 0,316 & Podlage za rast in razvoj \\
\hline
\end{tabular}

V drugem testnem anketiranju so se izoblikovali 3 sklopi oziroma faktorji: možnosti za delovno samorealizacijo, pogoji dela ter delovni odnosi in sodelovanje. Sklop 'pogoji dela' zajema izjave, ki obsegajo širši kontekst delovnih odnosov in sodelovanja skozi dejavnike kot so kakovost dela sodelavcev, komunikacija in počutje $\mathrm{v}$ delovnem okolju, sodelovanje ter 
dojemanje vsebine dela. Cronbachov alfa koeficient za nabor šestih izjav v sklopu 'pogoji dela' znaša 0,847. Sklop 'možnosti za delovno samorealizacijo' zajema dejavnike, ko so občutek upoštevanosti na delu, možnost pokazati znanje in podati predloge, občutek pomembnosti dela, upoštevanje delavčevih predlogov s strani vodje, samostojnost pri delu, odgovornost za strokovni razvoj, obstoj možnosti za strokovni razvoj, pričakovanja vodje. Cronbachov alfa koeficient za nabor osmih izjav v sklopu 'možnosti za delovno samorealizacijo' znaša 0,866. Sklop 'delovni odnosi in sodelovanje' zajema dejavnike o kakovosti dela sodelavcev, komunikaciji v delovnem okolju, sodelovanju, počutju in vsebina dela. Cronbachov alfa koeficient za nabor petih izjav v sklopu 'delovni odnosi in sodelovanje' znaša 0,845 .

$\mathrm{V}$ tabeli tri je predstavljen pregled razporeditve anketirancev glede na interval vrednosti na lestvici delovne zavzetosti in motivacije. Največji delež anketiranih (Tabela 3) v drugem testnem anketiranju predstavljajo tisti, ki imajo povprečno vrednost na celotni lestvici 3,45 ali več. Kar predstavlja 10 krat večji delež od tistih, na spodnjem delu intervala, to je anketiranih, s povprečno vrednostjo 2,44 ali manj na celotni lestvici.

Tabela 3. Preglede razporeditve anketirancev glede na interval vrednosti na lestvici delovne zavzetosti in motivacije

\begin{tabular}{lll}
\hline Interval vrednosti na lestvici & $\mathbf{N}$ & $\mathbf{\%}$ \\
\hline do vključno $\mathbf{2 , 4 4}$ & 13 & 6,5 \\
od vključno $\mathbf{2 , 4 5}$ do $\mathbf{3 , 4 4}$ & 54 & 27,0 \\
od vključno $\mathbf{3 , 4 5}$ & 133 & 66,5 \\
Skupaj & 200 & 100,0 \\
\hline
\end{tabular}

Legenda: N - število anketirancev, \% - odstotek anketirancev

\section{Razprava}

Čeprav se je po rezultatih prvega pilotnega anketiranja kazalo, da je smiselno izključiti 2 izjavi iz prvotnega nabora (ki pa so zaradi vsebinske dodane vrednosti tako pomembne, da smo jih tudi po rezultatih prvega testnega anketiranja svetovali obravnavati, in sicer ločeno od lestvice), je drugo pilotno anketiranje pokazalo, da bilo smiselno $\mathrm{v}$ analizo vključiti vse $\mathrm{v}$ prvotni nabor izjav izbrane izjave. V drugem pilotnem testiranju so se izoblikovali 3 sklopi, ki se vsebinsko v večjem delu prekrivajo z rezultati prvega pilotna testiranja kljub temu, da se je izoblikoval 1 faktor manj kot $\mathrm{v}$ prvem pilotnem testiranju (podrobneje predstavljeno $\mathrm{v}$ tabeli 2).

Medtem ko smo oblikovanje vsebinskih sklopov delovne zavzetosti in motivacije na primeru testiranega nabora izjav v vprašalniku v prvem pilotnem testiranju primerjali z vsebinskimi sklopi iz Gallupove lestvice (Inc, 2007) in novejše lestvice, ki je bila razvita na podlagi sodelovanja izkušenih kadrovskih managerjev in strokovnjakov na področju (Shrotryia in Dhanda, 2019), je bil cilj drugega testiranja preveritev skladnosti z rezultati prvega testiranja. Drugo pilotno testiranje je pokazalo dvoje: jasnejšo sliko in delitev indikatorjev po faktorjih ter veliko prekrivanje $\mathrm{z}$ rezultati prve faze testiranje kljub temu, da je število faktorjev drugega testiranja 3 medtem ko je bilo število faktorjev v prvem testiranju 4. Primerjava 
razporeditve dejavnikov po faktorjih glede na prvo in drugo testno anketiranje je razvidno $\mathrm{v}$ tabeli 2. Največjo spremembo v izoblikovani strukturi opazimo v tem, da so se dejavniki, ki so nasičevali faktor 'moje mikro okolje' prerazporedili med 3 faktorje, ki so se izoblikovali v drugem testnem anketiranju, ravno tako sta se v novo 3 delno faktorsko strukturo umestili 2 izjavi, ki sta v faktorski analizi prvega testnega anketiranja odstopali. Faktor 'delovni odnosi in sodelovanje' nasičujejo dejavniki, ki so v prvem testnem anketiranju nasičevali vsebinsko soroden faktor 'čemu pripadam' in dveh dejavnikov faktorja 'moje mikro okolje'. Faktor 'pogoji dela' večinsko nasičujejo dejavniki, ki so v prvem testnem anketiranju nasičevali faktor 'podlage za rast in razvoj', ki je z izločitvijo dejavnika 'odgovornost za strokovni razvoj' postal jasnejši in tesneje povezljiv z neposrednimi pogoji dela, ki so večinsko v domeni delodajalca, to je, večinsko niso odgovornost delavca. Faktor 'možnosti za delovno samorealizacijo' večinsko nasičujejo dejavniki faktorja 'kaj lahko ponudim' iz prvega testnega anketiranja $\mathrm{z}$ dodatnimi, glede na prvo testno anketiranje prerazporejenimi dejavniki občutka upoštevanosti, samostojnosti pri delu in odgovornosti za razvoj, kar jasneje izoblikuje vsebino faktorja. In kaže na kombinacijo dejavnikov na katere ima večinski vpliv delavec ter tistih, na katere ima večinski vpliv delodajalec in ki kažejo možnosti za delovno samorealizacijo v širšem smislu. Z vidika potenciala, ki ga nudi podjetje in potenciala, ki ga nosi delavec sam.

Na podlagi ugotovitev faktorske analize kot rečeno končna različica vprašalnika obsega vseh 19 v prvotni nabor vključenih vprašanj in nudi vhodno informacijo na različnih področjih razvojne aktivnosti kadrovske službe, kot so spremljanje novo zaposlenih, spremljanje neželenih odhodov, pogovor $\mathrm{z}$ delavci $\mathrm{s}$ sklenjenimi pogodbami o izobraževanju idr. Prilagojena različica je lahko uporabljena tudi za druge ciljne skupine, kot so štipendisti, dijaki in študenti na praktičnem usposabljanju idr.. Delitev po sklopih, ki so se izoblikovali, je vsebinsko pomembna in kaže stanje zavzetosti in motivacije posameznega delavca (ali organizacije kot celote) pri posameznem sklopu. Zato nam tako organizirana lestvica nudi možnost, da delovno zavzetost in motivacijo zaposlenih interpretiramo kot celoto (upoštevajoč vseh 19 indikatorjev) ali skozi prizmo stanja posameznega vsebinskega sklopa.

Zaloga vrednosti je pri vsakem dejavniku enaka in je razporejena od vrednosti 1 'nikakor ne drži' do 5 'popolnoma drži'. Pri tem morata biti podjetje in razvojno kadrovska služba pozorna na vsak interval vrednosti, na ravni posameznega dejavnika, posameznega sklopa, ki ga tvori več dejavnikov ter na ravni celotne lestvice. Vsak izmed intervalov vrednosti zahteva drugačen pristop obravnave in aktivnosti.

Posebna pozornost mora biti usmerjena $\mathrm{v}$ zaposlene, katerih povprečna vrednost pri vseh indikatorjih (ali smiselno pri posameznem sklopu oziroma dejavniku) delovne zavzetosti in motivacije skupaj znaša 2,44 ali manj. Gre za tiste, ki bi jih bilo mogoče označiti po zgledu Gallupovega 12Q vprašalnika kot aktivno nezavzete ali tudi namerno nasprotujoče. Pri tej skupini zaposlenih je nujen premislek o potencialu in realnih možnostih za doseganje pozitivnih sprememb ter za to potrebnih konkretnih aktivnosti v prihodnje. Večji delež zaposlenih $\mathrm{v}$ tem intervalu vrednosti je hkrati tudi signal organizaciji, da mora nujno aktivno pristopiti k razvoju delovne zavzetosti in njenih tvornih delov ter hkrati tudi premisliti na 
katerih posamičnih dejavnikih bo največji poudarek kratkoročno, srednjeročno in dolgoročno. To je še toliko bolj pomembno, če merjenje $\mathrm{v}$ organizaciji pokaže, da je povprečna vrednost na celotni lestvici na ravni celotne organizacije relativno nizka, na primer 3 ali manj. Glede na to, da drugo pilotno testiranje kaže, da so povprečne vrednoti pri indikatorjih relativno visoke (tabela 2), saj je le pri dveh indikatorjih povprečna vrednost pod 3, je za organizacijo izmed iztočnic, ki so pomembne za uvedbo dodatnih aktivnosti, ki bi dvignile raven delovne zavzetosti situacija, ko povprečna vrednost na ravni celotne organizacije pade pod 3 (se pravi, ko se povprečje ne nagiba $\mathrm{k}$ temu da je raven dejavnikov, ki jih vprašalnik zajema zagotovljena do te mere, da bi lahko rekli, da držijo). V takih primerih je mogoče oceniti, da so posamezniki, katerih povprečje znaša 2,44 ali manj, $v$ večji meri rezultat dogajanja na ravni organizacije, ne le razlogov izključno na lastni strani.

Naslednji interval predstavlja povprečna vrednost med 2,45 in 3,44, ki jo dosegajo zaposleni, ki so mogoče zadovoljni pri delu, a niso zavzeti ali pa delovna zavzetost ni na tako visoki ravni, da bi bila optimalna ali na tako nizki, da ne bi bilo mogoče izboljšanje. Pri teh zaposlenih ne gre za (ne)namerno nekonstruktivno ravnanje, možnosti za izboljšave pa so vseeno nujne na ravni posameznega sklopa ali celote. Hkrati pa so realneje dosegljive kot pri aktivno nezavzetih. Tudi v tem primeru je potrebno pogledati, kaj se dogaja s povprečjem na ravni celotne organizacije in na tej podlagi planirati nadaljnje aktivnosti.

Tretji interval vrednosti tvorijo zavzeti zaposleni, pri katerih povprečna vrednost za vse indikatorje skupaj znaša 3,45 ali več in predstavljajo tisti kader za katerega je mogoče domnevati, da so v večji meri zavzeti, motivirani in predani delu. Pri teh zaposlenih je ključno ohranjati raven zavzetosti z zagotavljanjem ustreznih možnosti za nadaljnji delovno strokovni razvoj in izboljšavo pri na ravni posamičnega dejavnika. Upoštevajoč, da bistveno zanemarjanje enega dejavnika in njegov upad na prenizko raven lahko negativno sooblikuje tudi druge dejavnike. Vidimo, da je $\mathrm{v}$ primeru testirane lestvice in rezultatov testnega anketiranja delež takih, ki označujemo kot delovno zavzete višje kot to velja za nekatere druge lestvice. V povezavi z Gallupovo lestvico se na primer poroča, da je med zaposlenimi $34 \%$ tistih, ki so delovno zavzeti (Harter, 2018). Pri tem je pomembno vprašanje kriterijev razmejitve med posameznimi razredi zavzetosti, ki ga posamezna lestvica postavi in na tej podlagi interpretira podatke. Glede na lestvico odgovorov v primeru v članku predstavljenega vprašalnika, ki so za vse indikatorje obravnavane lestvice enaki in gredo od vrednosti 1 do vrednosti 5 , je predstavljeni pristop najprimernejši. Če pa želimo iskati najbolj delovno zavzete in motivirane med zaposlenimi, oziroma, če želimo ugotoviti kolikšen je delež takih v konkretni organizaciji, je smiselno iskati med tistimi, ki so nad povprečjem celotne organizacije ob vsakokratnem merjenju.

Ob ugotavljanju delovne zavzetosti in motivacije na podlagi v članku predstavljene lestvice (primerljivo pa to velja tudi za vse druge) je potrebno poudariti in upoštevati, da je mogoče pričakovati, da lahko odgovore zaposlenega sooblikuje več dejavnikov, ne le raven posameznikove delovne zavzetosti in motivacije ali stanje na posameznih dejavnikih, ki jih lestvica obsega. Tudi rezultati faktorske analize na podlagi predstavljenih rezultatov po 
rotirani rešitvi kažejo, da je z dobljenimi faktorji mogoče pojasniti 53,79\% variabilnosti delovne zavzetosti in motivacije na vzorcu. Zato je za nadaljnje kakovostno razvojno kadrovsko delo $\mathrm{v}$ praksi pomembno rezultate navedenega vprašalnika razumeti predvsem $\mathrm{v}$ kontekstu izhodiščne točke za nadaljnje aktivnosti tako v povezavi z razvojem posameznika, kot možnosti za izboljšave na ravni organizacije.

Testirana in v članku predstavljena lestvica je dovolj dolga, da zajema vse bistvene dejavnike (tabela 2), ki sooblikujejo delovno zavzetost in motivacijo. Hkrati pa ni predolga, da bi tvegali večjo možnost za avtomatično odgovarjanje brez vsebinskega premisleka, ki se pojavi pri (daljših) blokih vprašanj z enako lestvico odgovorov, ko anketirani na vsa ali večino vprašanj odgovarjajo $\mathrm{v}$ določenem vzorcu oziroma $\mathrm{z}$ le majhnim obsegom zaloge vrednosti (npr. samo 3 na 5-stopenjski lestvici) (Allen in Van der Velden, 2005, str. 12). Anketiranci v takih primerih zaznavajo način, na katerega so vprašanja sestavljena, zato ne preberejo posameznega podvprašanja, temveč avtomatično dajo enake odgovore ali vzorce odgovorov (Paladin idr., 2020, str. 712). Zato je kot taka zelo primerna za uporabo v neposredni praksi organizacij.

Razvojna pot vprašalnika kot jo razumemo v povezavi s predstavljenim vprašalnikom $\mathrm{v}$ tem članku gre nujno $\mathrm{v}$ smeri nadaljnje validacije in testiranja ob hkratni neposredni uporabi $\mathrm{v}$ praksi. Nadaljnjo razvojno pot vprašalnika razumemo kot nujno četrto fazo testiranja, ki se nikoli ne zaključi, če naj odraža spremembe v kadrovski in organizacijski stroki in praksi. Torej, kljub temu, da je vprašalnik nastal na podlagi večfaznega kompleksnega postopka in analize, ki je pokazala zelo visoko notranjo konsistentnost celotne lestvice tako $\mathrm{v}$ prvem testnem anketiranju kot $\mathrm{v}$ drugem testnem anketiranju, kot uvod $\mathrm{v}$ morebitno uporabo $\mathrm{v}$ praksi vsakega podjetja priporočamo izvedbo eksploratorne faktorske analize zaradi podrobnejšega vpogleda v strukturiranost znotraj lestvice na primeru konkretnega kolektiva.

\section{Zaključek}

Redno merjenje delovne zavzetosti in motivacije na podlagi preizkušenega, testiranega in skozi leta nespremenjenega vprašalnika je lahko dober kazalnik za potrebe spremljanja kakovosti upravljanja s človeškimi viri in ugotavljanja trenda na področju delovne zavzetosti in motivacije zaposlenih ter zagotavljanja pogojev, ki jo sooblikujejo. Do določene mere pomenijo tudi vrednotenje vodstvene funkcije.

Pri razvoju in testiranju vprašalnika oziroma lestvice, ki je predstavljena v članku, smo upoštevali več izhodišč, da bi zagotovili kar se da visoko raven kakovosti in praktične uporabnosti končne oblike vprašalnika. Preverili smo uveljavljene pristope in prakso na področju merjenja delovne zavzetosti in motivacije zaposlenih. Testiranje vprašalnika je potekalo $\mathrm{v}$ več fazah, $\mathrm{v}$ katerih smo pridobili informacije, na kakšen način vprašalnik prilagoditi konkretnemu okolju, ali je dolžina vprašalnika sprejemljiva, ali je vsebina vprašalnika dovolj jasna ter identificirali sklope $\mathrm{v}$ vprašalnik zajetih dejavnikov, ki sooblikujejo delovno zavzetost in motivacijo zaposlenih. 
Za uporabo v praksi je posebej potrebno opozoriti, kako pomembna je odločitev oziroma premislek o tem ali boste vprašalnik izvajali anonimno ali ne. Ob zagotovljeni anonimnosti bodo zaposleni pri odgovarjanju bolj iskreni, saj ne bodo čutili potrebe po tem, da se, vsaj pri nekaterih dejavnikih, pokažejo v kar se da pozitivni luči. V osnovi gre namreč za temo, ki jo lahko nekateri zaposleni razumejo kot potencialno občutljivo in pri kateri is bodo zaposleni prizadevali odgovarjati družbeno/organizacijsko bolj sprejemljivo, če bodo vedeli, da ne odgovarjajo anonimno (Castro, 2013; Krumpal, 2013; Näher in Krumpal, 2012; Wolter in Preisendörfer, 2013). Na drugi strani pa anonimni odgovori ne bodo pokazali na kakšen način pristopiti posameznemu zaposlenemu z namenom razvoja ali ohranitve delovne zavzetosti. $\mathrm{Na}$ drugi strani, če želi podjetje vprašalnik o delovni zavzetosti in motivaciji zaposlenih vpeljati kot eno izmed orodij letnih in razvojnih razgovorov, anonimnost ni ena od možnosti. Omogoča pa individualen pristop k planiranju aktivnosti.

Redno merjenje delovne zavzetosti zaposlenih ima lahko velik pomen za vodje in kadrovske strokovnjake predvsem $v$ smislu fokusiranega dela na področju razvoja kadrov na eni strani ter oblikovanja delovnih mest, kadrovsko izbirnih postopkov in odnosov z zaposlenimi, ki bodo krepili delovno zavzetost in posledično produktivnost na drugi strani. Spremljanje delovne zavzetosti predstavlja eno izmed podlag za oblikovanje srednjeročnih in dolgoročnih strategij za doseganje visoke stopnje produktivnosti na delovnem mestu. Ter na ta način tudi razvoja trajnostne in temeljne konkurenčne prednosti (Kim idr., 2012, str. 267), ki jo v današnjem hitro spreminjajočem se poslovnem okolju predstavljajo delovno zavzeti zaposleni. Zato ne preseneča, da je preučevanje delovne zavzetosti deležno vedno večje pozornosti tako s strani raziskovalcev kot tudi izvajalcev s področja razvoja človeških virov, razvoja organizacije, psihologije in poslovanja (Kwon in Park, 2019, str. 353).

Tudi najbolj uveljavljeni merski instrumenti so za praktično uporabo, ki bo podlaga za dejanske nadaljnje aktivnosti na kadrovskem področju ali v poslovanju podjetij, primerni le ob kritičnem premisleku o njihovi uporabnosti $\mathrm{v}$ konkretnem okolju in $\mathrm{v}$ konkretni organizaciji. Ena večjih dodanih vrednosti v članku predstavljenega vprašalnika je to, da je bil oblikovan in v vseh fazah testiran v slovenskem delovnem okolju. Obenem pa poudarjamo, da je cilj predstavljenega vprašalnika najti pot $\mathrm{v}$ redno prakso organizacij ob njegovem hkratnem nadaljnjem razvoju, ki ga razumemo kot njegovo četrto razvojno fazo. To je obenem tudi omejitev oziroma nadaljnji razvojni potencial v članku predstavljene raziskave in vprašalnika. Zato je nadaljnja uporaba vprašalnika $v$ raziskovalne namene dobrodošla. 


\section{Reference}

1. Allen, J. in Van der Velden, R. (2005). The role of self-assessment in measuring skills. Research Centre for Education and the Labour Market. Pridobljeno na http://roa.sbe.maastrichtuniversity.nl/roanew/wpcontent/uploads/2014/02/REFLEX_Workingpaper02_Role_of_Self_Assessment_of_Skills_28apri 12005.pdf

2. Bakertzis, E. in Myloni, B. (2020). Profession as a major drive of work engagement and its effects on job performance among healthcare employees in Greece: A comparative analysis among doctors, nurses and administrative staff. Health Services Management Research. https://doi.org/10.1177/0951484820943592

3. Bakovnik, N. (2018). Gallupovo poročilo o zavzetosti zaposlenih na delovnem mestu 2013. Združenje svetov delavcev Slovenije. Pridobljeno na http://www.delavskaparticipacija.com/priloge/2018-1.docx

4. Bromley, A. P., Boran, J. R. in Myddelton, W. A. (2016). Investigating the baseline skills of research students using a competency-based self-assessment method: Active Learning in Higher Education. https://doi.org/10.1177/1469787407077992

5. Castro, R. (2013). Inconsistent Respondents and Sensitive Questions. Field Methods, 25(3), 283298. https://doi.org/10.1177/1525822X12466988

6. Chaudhary, R., Rangnekar, S. in Barua, M. K. (2012). Relationships between occupational self efficacy, human resource development climate, and work engagement. Team Performance Management: An International Journal, 18(7/8), 370-383. https://doi.org/10.1108/13527591211281110

7. Chemingui, H. in Ben lallouna, H. (2013). Resistance, motivations, trust and intention to use mobile financial services. International Journal of Bank Marketing, 31(7), 574-592. https://doi.org/10.1108/IJBM-12-2012-0124

8. Cowan, D. T., Wilson-Barnett, J. in Norman, I. J. (2007). A European survey of general nurses' self assessment of competence. Nurse Education Today, 27(5), 452-458. https://doi.org/10.1016/j.nedt.2006.08.008

9. Curyto, K. J. in Vriesman, D. K. (2015). Development of the Knowledge of Dementia Competencies Self-Assessment Tool: American Journal of Alzheimer's Disease \& Other Dementias ${ }^{\circledR}$. https://doi.org/10.1177/1533317515581703

10. Danish, R. in Usman, A. (2010). Impact of Reward and Recognition on Job Satisfaction and Motivation: An Empirical study from Pakistan. International Journal of Business and Management, 5(2), 159-167. https://doi.org/10.5539/ijbm.v5n2p159

11. Darling, S. M. in Gallagher, P. A. (2016). Using Self-Assessments in Early Intervention Training: Journal of Early Intervention, 25(3), 219-227. https://doi.org/10.1177/105381510302500306

12. Enosh, G., Tzafrir, S. S. in Stolovy, T. (2015). The Development of Client Violence Questionnaire (CVQ). Journal of Mixed Methods Research, 9(3), 273-290. https://doi.org/10.1177/1558689814525263

13. Fox, C. L., Gadd, D. in Sim, J. (2015). Development of the Attitudes to Domestic Violence Questionnaire for Children and Adolescents. Journal of Interpersonal Violence, 30(14), 25062525. https://doi.org/10.1177/0886260514553115

14. Griffin, M. L., Hogan, N. L., Lambert, E. G., Tucker-Gail, K. A. in Baker, D. N. (2010). Job Involvement, Job Stress, Job Satisfaction, and Organizational Commitment and the Burnout of 
Correctional Staff. Criminal Justice and Behavior, 37(2), 239-255.

https://doi.org/10.1177/0093854809351682

15. Gupta, M. in Shukla, K. (2018). An Empirical Clarification on the Assessment of Engagement at Work. Advances in Developing Human Resources, 20(1), 44-57.

https://doi.org/10.1177/1523422317741692

16. Harter, J. (2018). Employee Engagement on the Rise in the U.S. Gallup.Com. Pridobljeno na https://news.gallup.com/poll/241649/employee-engagement-rise.aspx

17. Ho, V. T. in Astakhova, M. N. (2018). Disentangling passion and engagement: An examination of how and when passionate employees become engaged ones. Human Relations, 71(7), 973-1000. https://doi.org/10.1177/0018726717731505

18. Iglesias, C. in Torgerson, D. (2000). Does Length of Questionnaire Matter? A Randomised Trial of Response Rates to a Mailed Questionnaire. Journal of Health Services Research \& Policy, 5(4), 219-221. https://doi.org/10.1177/135581960000500406

19. Inc, G. (2007). Where Employee Engagement Happens. Gallup.Com. Pridobljeno na https://news.gallup.com/businessjournal/102496/Where-Employee-Engagement-Happens.aspx

20. Kim, W., Kolb, J. A. in Kim, T. (2012). The Relationship Between Work Engagement and Performance: A Review of Empirical Literature and a Proposed Research Agenda. Human Resource Development Review, 12(3), 248-276. https://doi.org/10.1177/1534484312461635

21. Kogovšek, T. (2005). Zanesljivost in veljavnost v kvalitativnem in kvantitativnem raziskovanju. Teorija in praksa, 42(1), 256-278.

22. Krumpal, I. (2013). Determinants of social desirability bias in sensitive surveys: A literature review. Quality \& Quantity, 47(4), 2025-2047. https://doi.org/10.1007/s11135-011-9640-9

23. Kwon, K. in Park, J. (2019). The Life Cycle of Employee Engagement Theory in HRD Research. Advances in Developing Human Resources, 21(3), 352-370. https://doi.org/10.1177/1523422319851443

24. May, D. R., Gilson, R. L. in Harter, L. M. (2004). The psychological conditions of meaningfulness, safety and availability and the engagement of the human spirit at work. Journal of Occupational and Organizational Psychology, 77(1), 11-37. https://doi.org/10.1348/096317904322915892

25. McCarthy, I. O., Moonesinghe, R. in Dean, H. D. (2020). Association of Employee Engagement Factors and Turnover Intention Among the 2015 U.S. Federal Government Workforce. SAGE Open, 10(2), 1-11. https://doi.org/10.1177/2158244020931847

26. Näher, A.-F. in Krumpal, I. (2012). Asking sensitive questions: The impact of forgiving wording and question context on social desirability bias. Quality \& Quantity, 46(5), 1601-1616. https://doi.org/10.1007/s11135-011-9469-2

27. Paladin, M. (2020). Merjenje delovne zavzetosti in motivacije zaposlenih. HR\&M : strokovna revija za področje razvoja organizacij in vodenja ljudi pri delu, 6 (26 (feb./mar. 2020)), 8-11.

28. Paladin, M., Kogovšek, T. in Pavlin, S. (2020). How do the particular characteristics of lesseducated employees with disabilities impact survey implementation? Work, 65(4), 707-719. https://doi.org/10.3233/WOR-203125

29. Pogačnik, V. (1993). Lestvica delovnih motivov. Psihološka obzorja, 2(3/4), 143-157.

30. Pogačnik, V. (2000). Uporaba Lestvice delovnega zadovoljstva v slovenskih podjetjih. Psihološka obzorja, 9(4), 105-114.

31. Schaufeli, W. B., Salanova, M., González-romá, V. in Bakker, A. B. (2002). The Measurement of Engagement and Burnout: A Two Sample Confirmatory Factor Analytic Approach. Journal of Happiness Studies, 3(1), 71-92. https://doi.org/10.1023/A:1015630930326 
32. Schembre, S. M., Durand, C. P., Blissmer, B. J. in Greene, G. W. (2015). Development and Validation of the Cognitive Behavioral Physical Activity Questionnaire. American Journal of Health Promotion, 30(1), 58-65. https://doi.org/10.4278/ajhp.131021-QUAN-539

33. Sekhar, C., Patwardhan, M. in Vyas, V. (2018). Linking Work Engagement to Job Performance Through Flexible Human Resource Management. Advances in Developing Human Resources, 20(1), 72-87. https://doi.org/10.1177/1523422317743250

34. Shrotryia, V. K. in Dhanda, U. (2019). Content Validity of Assessment Instrument for Employee Engagement. SAGE Open, 9(1), 1-7. https://doi.org/10.1177/2158244018821751

35. Staley, C. C. in Shockley-Zalabak, P. (1986). Communication Proficiency and Future Training Needs of the Female Professional: Self-Assessment vs. Supervisors' Evaluations: Human Relations, 39(10), 891-902. https://doi.org/10.1177/001872678603901001

36. Stufflebeam, D. L. in Wingate, L. A. (2016). A Self-Assessment Procedure for Use in Evaluation Training: American Journal of Evaluation, 26(4), 544-561. https://doi.org/10.1177/1098214005279730

37. Tavakol, M. in Dennick, R. (2011). Making sense of Cronbach's alpha. International Journal of Medical Education, 2, 53-55. https://doi.org/10.5116/ijme.4dfb.8dfd

38. Velagapudi, S. P. in Ray, G. G. (2017). Development of a Seating Comfort Questionnaire for Motorcycles. Human Factors, 59(8), 1249-1262. https://doi.org/10.1177/0018720817735929

39. Weer, C. H. in Greenhaus, J. H. (2020). Managers' Assessments of Employees' Organizational Career Growth Opportunities: The Role of Extra-Role Performance, Work Engagement, and Perceived Organizational Commitment. Journal of Career Development, 47(3), 280-295. https://doi.org/10.1177/0894845317714892

40. Wolter, F. in Preisendörfer, P. (2013). Asking Sensitive Questions: An Evaluation of the Randomized Response Technique Versus Direct Questioning Using Individual Validation Data. Sociological Methods \& Research, 42(3), 321-353. https://doi.org/10.1177/0049124113500474

Mag. Marija Paladin, ima več kot desetletje izkušenj na kadrovskem področju, trenutno vodi službo za kadre. Je magistra znanosti s področja managementa. Raziskuje področje razvoja ljudskih potencialov, vloge komunikacije $u$ formalnih vlogah posameznika in organizacije, timskega dela ter različne aspekte organizacijske uspešnosti in učinkovitosti. Je avtorica knjige Neverbalna komunikacija: dopolniti besede in biti prepričljiv ter več strokovnih in znanstvenih člankov.

\section{Abstract: \\ Development of a Questionnaire on Work Engagement and Employee Motivation}

Research Question (RQ): What is the way to develop a questionnaire on work engagement and employee motivation, which can also be a signpost for the development of the organization?

Purpose: The aim and purpose are to present the development of a multidimensional, self-applied questionnaire, which on the basis of self-assessment offers an insight into the state of work engagement and motivation of employees and offers a starting point for improvements at the organizational level.

Method: The stages of questionnaire development in which quantitative and qualitative methodology are integrated are presented. In this paper the emphasis is on the results of the quantitative phase - the second test survey. 
Revija za univerzalno odličnost / Journal of Universal Excellence,

Junij / June 2021, leto / year 10, številka / number 2, str. / pp. 136-154.

Results: The scale formed through both phases of the test survey indicates a high internal consistency. In the second test survey, 3 factors are formed through which the factors of work commitment and motivation of employees are presented according to 'on work relations and cooperation', 'working conditions' and 'opportunities for work self-realization'.

Organization: Assessing the work commitment and motivation of employees for the organization, on the one hand, is a starting point for concrete work in the field of development human resources, and on the other hand, information on possible weaknesses that need to be strengthened to improve the competitive position.

Society: Employed and motivated individuals are the bearer of development and productivity and the search for more optimal solutions in a constantly changing business and social environment.

Originality: The contribution of this study is twofold - methodological and practical. The developed questionnaire offers practitioners, experts and researchers the possibility of using a scale designed and tested in our environment for practical use in the HR activities of the organization as well as for the purpose of further research.

Limitations/Future Research: The questionnaire development process is presented as an open path with the fourth phase, which is not completed and as such is also highlighted in the article. Therefore, an invitation to further testing is also clearly expressed through practical application.

Keywords: work engagement, motivation, leadership, HR development, organizational development, questionnaire.

Copyright (c) Marija PALADIN

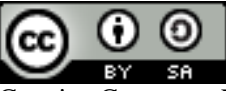

Creative Commons License

This work is licensed under a Creative Commons Attribution-ShareAlike 4.0 International License. 